MESAS EIXO 2:

"PSICANÁLISE: DIÁLOGO NAS FRONTEIRAS" 


\section{A expansão do estado de exceção e as fronteiras do capitalismo 93}

\section{Gilberto Bercovici 94}

O jurista alemão Carl Schmitt (1888-1985) afirma que só a partir do estado de exceção pode ser pensado, em toda a sua profundidade, o problema da realização do direito, pois ele é a essência do Estado e da manutenção da unidade política. A normalidade não demonstra nada; a exceção prova tudo, pois a regra vive da exceção.

Na estrutura do Estado, o poder soberano, simultaneamente, define a ordem ou declara a ausência dela. Mas, toda ordem repousa sobre uma decisão, não sobre uma norma. Assim, o estado de exceção não seria apenas o oposto de uma ordem constitucional da normalidade, mas seu fundamento, pois é o que motiva a decisão do soberano. Este decide sobre a situação na qual o direito pode valer95.

A definição de soberania a partir da excepcionalidade chama a atenção para um aspecto da realidade ignorado pelos juristas, embora perca seu significado na normalidade. A situação de normalidade significa que o Estado conseguiu manter a ordem, e isso, por contraposição, mostra como o a exceção é uma hipótese fundamental para o funcionamento do sistema. Não se pode ignorar nem o que se define como normalidade, nem a exceção, sob pena de ignorar-se a realidade. O pensamento que nega a exceção é imobilista, recusando-

\footnotetext{
93 Trabalho apresentado na mesa "Os estados de exceção e as brechas nas fronteiras” no II Simpósio Bienal SBPSP “Fronteiras da Psicanálise: a clínica em movimento” no dia 29 de agosto de 2020.

94 Professor Titular da Faculdade de Direito da USP, Doutor em Direito do Estado e Livre docente em Direito Econômico pela USP, Professor dos Programas de Pós-Graduação em Direito da UNINOVE e da Universidade Presbiteriana Mackenzie.
}

95 Carl SCHMITT, Politische Theologie: Vier Kapitel zur Lehre von der Souveränität, $7^{\mathrm{a}}$ ed, Berlin, Duncker \& Humblot, 1996, pp. 13-21; Hasso HOFMANN, Legitimität gegen Legalität: Der Weg der politischen Philosophie Carl Schmitts, $4^{\text {a }}$ ed, Berlin, Duncker \& Humblot, 2002, pp. 56-62; Pier Paolo PORTINARO, La Crisi dello Jus Publicum Europaeum: Saggio su Carl Schmitt, Milano, Edizioni di Comunità, 1982, pp. 8085; Giorgio AGAMBEN, Homo Sacer: Il Potere Sovrano e la Nuda Vita, Torino, Einaudi, 1995, pp. 19-24 e 31-34; Carlo GALLI, Genealogia della Politica: Carl Schmitt e la Crisi del Pensiero Politico Moderno, Bologna, Il Mulino, 1996, pp. 337-341, 345-361 e 514-516; Giorgio AGAMBEN, Stato di Eccezione, Torino, Bollati Boringhieri Editore, 2003, pp. 33-34 e 41-54 e Gilberto BERCOVICI, Constituição e Estado de Exceção Permanente: Atualidade de Weimar, Rio de Janeiro, Azougue Editorial, 2004, pp. 65-77. 
se a reconhecer o verdadeiro valor da ordem. Por sua vez, o pensamento que nega a normalidade é ocasionalístico, recusando-se a enxergar a regularidade jurídica ou política ${ }^{96}$.

O direito constitucional, acostumado a lidar com regras, tem dificuldades em lidar com a exceção97. Apesar disso, a maior parte dos autores é favorável à constitucionalização da exceção, com o objetivo de racionalizar a proteção extraordinária do Estado, e procura incorporá-la ao ordenamento jurídico. A previsão constitucional dos instrumentos de exceção seria uma forma de afirmação da democracia 98 . A questão dos poderes de exceção no Estado constitucional diz respeito sempre às escolhas sobre o que deve ser preservado99.

A questão da exceção no direito público não trata apenas de descartar a legislação aplicável em decorrência de certas circunstâncias, mas diz respeito também à subtração das relações normais entre governantes e governados. A dificuldade em tratar da exceção diz respeito à aporia presente na noção de que a "necessidade faz a lei" ${ }^{100}$.

Um dos motivos desta aporia é o fato de que um governo subordinado ao direito nunca existiu em sua plenitude. O Estado é uma entidade soberana que busca assegurar a sua própria preservação. Neste sentido, existe uma constitutional reason of state, em que a razão de Estado está vinculada a temas como defesa constitucional ou interesse nacional. A ideia de razão de Estado precisa ser reconcebida e reabilitada para a democracia, no sentido da defesa da ordem constitucional. Na questão da sobrevivência do Estado, a segurança interna e a externa estão vinculadas, sendo um problema que diz respeito tanto a um governo autoritário como a um constitucional101.

\footnotetext{
${ }^{96}$ Roman SCHNUR, Individualismo e Assolutismo: Aspetti della Teoria Política Europea Prima di Thomas Hobbes (160o-1640), Milano, Giuffrè, 1979, pp. 48-56.

${ }^{97}$ Sobre a distinção entre normalidade e exceção, vide Ernst-Wolfgang BÖCKENFÖRDE, "Die Krise in der Rechtsordnung: der Ausnahmezustand" in Krzysztof MICHALSKI (org.), Über die Krise, Stuttgart, KlettCotta, 1986, pp. 184-187.

98 Paul LEROY, L'Organisation Constitutionnelle et les Crises, Paris, L.G.D.J., 1966, pp. 34-45 e 47; Pedro Cruz VILLALÓN, Estados Excepcionales y Suspensión de Garantías, Madrid, Tecnos, 1984, pp. 17-19 e 2324 e Jorge Bacelar GOUVEIA, O Estado de Excepção no Direito Constitucional: Entre a Eficiência e a Normatividade das Estruturas de Defesa Extraordinária da Constituição, Coimbra, Almedina, 1998, vol. 2, pp. 1391-1400 e 1514-1540.

99 Gabriel L. NEGRETTO, El Problema de la Emergencia en el Sistema Constitucional, Buenos Aires, Editorial Ábaco, 1994, pp. 18-19.

100 François SAINT-BONNET, L'État d'Exception, Paris, PUF, 2001, pp. 1-2.

101 Carl J. FRIEDRICH, Constitutional Reason of State: The Survival of the Constitutional Order, Providence, Brown University Press, 1957, pp. 2-14 e 113-119; Helmut RUMPF, "Die Staatsräson im demokratischen Rechtsstaat”, Der Staat, vol. 19, 1980, pp. 286-292 e Gabriel L. NEGRETTO, El Problema de la Emergencia en el Sistema Constitucional cit., p. 25.
} 
O Estado deve garantir a proteção jurídica e a segurança, sem as quais é impossível o desenvolvimento do capitalismo e a edificação da economia de mercado. Mas o mercado não é exclusivamente econômico; ele diz respeito às relações sociais e políticas, ainda que a concepção proveniente de Adam Smith verdadeiro anti-Maquiavel - sustente a despolitização radical das relações socioeconômicas ${ }^{102}$.

A valorização da constituição como norma é utilizada para fazer frente ao discurso revolucionário da soberania popular. O constitucionalismo busca a estabilidade ameaçada pela interpretação radical e democrática da revolução. Mais do que isso, o ciclo polibiano das formas de governo (alternância de constituições boas e más) vai ser imobilizado pela pretensão de eternidade do liberalismo. O constitucionalismo e sua pretensão de permanência, caracterizada pela rigidez constitucional, tenta evitar a degenerescência da forma política liberal, buscando encerrar a contingência e o dinamismo da política expostos por Maquiavel. O constitucionalismo liberal tinha essa função, e, para garantir a ordem de mercado constitucional contra o eventual ressurgimento do poder constituinte, modificou-se o estado de exceção. A salvaguarda do Estado não é da instituição - que é indiferente à pessoa do titular do poder -, mas é a salvaguarda do soberano, de seu poder de fazer a constituição e as leis.

No Estado constitucional moderno, invoca-se a salvaguarda do Estado no sentido da salvaguarda da constituição - para justificar a violação da constituição. A constituição é violada para salvar o regime ${ }^{103}$. Da garantia do Estado passa-se à garantia da constituição.

Os constitucionalistas preocupam-se essencialmente com os meios jurídicos de controle dos poderes de crise, buscando uma fórmula perfeita que responda a todas as situações, atuando no campo da eficácia e do controle desses poderes. A preocupação concentra-se na justificação (sempre posterior à violação da regra) ou no fundamento (antes da atuação violadora) da utilização dos poderes excepcionais. Ou seja, a crise é entendida como um mero exercício

\footnotetext{
102 Otto HINTZE, "Wirtschaft und Politik im Zeitalter des modernen Kapitalismus" in Otto HINTZE, Soziologie und Geschichte: Gesammelte Abhandlungen zur Soziologie, Politik und Theorie der Geschichte, $2^{\text {a }}$ ed, Göttingen, Vandenhoeck \& Ruprecht, 1964, pp. 430-436 e Pierre ROSANVALLON, O Liberalismo Econômico: História da Idéia de Mercado, Bauru, EDUSC, 2002, pp. 8-10, 76-78 e 183-187.

103 François SAINT-BONNET, L'État d'Exception cit., pp. 34-42.
} 
normal de competências extraordinárias ${ }^{104}$; o legislador pensa que as crises podem ser enfrentadas sem sair da estrita legalidade.

Todavia, se a legislação de exceção permitiu resolver uma crise sem ultrapassar os limites legais, não significa que servirá para solucionar outra. As crises são imprevisíveis. No fundo, toda previsão de legislação de exceção é inútil. A legislação de exceção trata de algo do qual, na realidade, ela não consegue dar conta. A legitimação dos atos realizados durante a exceção depende do respaldo político e popular, não jurídico ${ }^{105}$.

A antecipação das crises pelos textos legais não ultrapassa a aporia do direito de necessidade, embora desloque o seu centro de gravidade. Em princípio, não há mais violação do direito. A discussão, agora, refere-se à constitucionalidade de um texto legislativo que autoriza a exclusão da incidência da constituição. Formalmente, a questão principal é o respeito ao procedimento. Funcionalmente, a legislação de exceção está ao lado da legislação normal. São ordens concorrentes.

Há, assim, uma espécie de "legalidade de crise" para a exceção, paralela à legalidade da normalidade ${ }^{106}$. A legislação sobre a exceção tenta evitar que a exceção vire regra, enquadrando as circunstâncias de crise para propiciar o retorno mais breve e menos traumático possível à normalidade. O problema é que este retorno não é uma questão jurídica formal, mas política. A salvaguarda da ordem democrática não depende do direito, mas dos cidadãos ${ }^{107}$.

A ruptura constitucional não pertence ao estado de exceção, que trata apenas de uma suspensão ou derrogação de uma parcela da ordem constitucional e por um período provisório ${ }^{108}$. Quando a ditadura constitucional busca se tornar permanente, torna-se inconstitucional, pois busca, por um golpe de Estado, alterar ou subverter a ordem constitucional que deveria proteger. Afinal, o bem protegido pelo estado de exceção é a ordem constitucional; não se trata de uma

\footnotetext{
104 François SAINT-BONNET, L'État d'Exception cit., pp. 15-16.

105 François SAINT-BONNET, L'État d'Exception cit., pp. 359-362, 366-376 e 380-384.

106 François SAINT-BONNET, L'État d'Exception cit., pp. 23-25 e Gilberto BERCOVICI, Soberania e Constituição: Para uma Crítica do Constitucionalismo, ${ }^{\mathrm{a}}$ ed, São Paulo, Quartier Latin, 2013, pp. 167-171, 176-177 e 216-219.

107 François SAINT-BONNET, L'État d'Exception cit., pp. 27 e 284.

108 Clinton ROSSITER, Constitutional Dictatorship: Crisis Government in the Modern Democracies, reimpr. New Brunswick/London, Transaction Publishers, 2002, pp. 294-295.
} 
violação ocasional ou casuística, mas uma violação com vistas à defesa da ordem constitucional ${ }^{109}$.

Apesar de o estado de exceção ter sido constitucionalizado a partir do século XIX, as novas manifestações do poder constituinte do povo, especialmente após a Primeira Guerra Mundial, vão instituir as constituições de compromisso do século $\mathrm{XX}$, nas quais a ordem constitucional não mais se limita a garantir a ordem do mercado. Pelo contrário, dirige-se, muitas vezes, contra os fundamentos dessa ordem.

Carl Schmitt percebeu, então, que o estado de exceção, no século XX, passa por uma profunda transformação. A exceção não é mais a garantia da ordem constitucional. Ela passa a ser utilizada das mais variadas formas, e permanentemente, mas não para garantir o Estado ou a constituição, e sim o capitalismo; ou, na expressão consagrada de Karl Polanyi, o "moinho satânico", que transforma os homens em massa, triturando as vidas do povo ${ }^{110}$.

A evolução desse sistema de exceção no decorrer do século $\mathrm{XX}$ vai da violência aberta, como o fascismo, à sutil e recente elaboração de uma constituição desvinculada do Estado e do poder constituinte do povo, para instituir e garantir a ordem do mercado. Apesar dos avanços e conquistas, o Estado social do segundo pós-guerra e os trinta anos de "consenso keynesiano" acabaram por se revelar uma exceção na história do capitalismo. As constituições democráticas e sociais vão, desde o início, enfrentar vários obstáculos para sua concretização, sendo apenas parcialmente cumpridas. O núcleo emancipatório das constituições sociais, na prática, foi suspenso. A suspensão da constituição social, no entanto, torna-se evidente com a nova crise econômica, a partir da década de 1970, e a contra-revolução neoliberal conservadora que não se limita mais a suspender ou bloquear as cláusulas sociais das constituições, mas busca a sua extirpação formal do texto constitucional ${ }^{111}$.

No decorrer do século XX, portanto, a distinção entre estado de exceção e normalidade deixou de ser absoluta, com a inutilidade dos meios tradicionais de exceção diante da exceção econômica. Há, simultaneamente, a proliferação e a heterogeneização das fronteiras, que deixam de ser apenas as linhas

\footnotetext{
109 Clinton ROSSITER, Constitutional Dictatorship cit., pp. 7-8 e Ernst-Wolfgang BÖCKENFÖRDE, "Die Krise in der Rechtsordnung: der Ausnahmezustand" cit., pp. 188-189.

${ }^{110}$ Karl POLANYI, The Great Transformation: The Political and Economic Origins of Our Time, $2^{\mathrm{a}} \mathrm{ed}$, Boston, Beacon Press, 2001, pp. 35 e 234 e Gilberto BERCOVICI, Soberania e Constituição cit., pp. 307-319. ${ }^{111}$ Gilberto BERCOVICI, Soberania e Constituição cit., pp. 319-326.
} 
geopolíticas de separação entre Estados, mas se tornaram instituições sociais complexas, marcadas por tensões e conflitos, espaços de gestão de pessoas e bens, onde se encontram a política e a violência, onde há a organização e a reorganização constante do capital ${ }^{112}$.

A ditadura constitucional deixou de ser temporária para se tornar uma estrutura permanente de governo, para enfrentar crises. Ou seja, há a banalização do estado de exceção. Formalmente, vigoram os princípios democráticos, mas, na prática, são constantemente suspensos ou violados. O estado de exceção, assim, não é um "raio caído de um céu azul" (expressão com a qual Marx descreve a imagem que os liberais franceses tinham do golpe de Estado de Luís Napoleão Bonaparte). Nem é o milagre de Carl Schmitt. Pelo contrário, de acordo com Giorgio Agamben, é o novo "paradigma de governo" 113.

De garantia do Estado, o estado de exceção passou a ser empregado na garantia da constituição, e, agora, consolida-se como garantia do capitalismo. Apesar dessas transformações, uma constante permanece: a tentativa permanente de exclusão de toda e qualquer forma de soberania popular ${ }^{114}$.

\footnotetext{
112 Sandro MEZZADRA \& Brett NEILSON, Border as Method, or, the Multiplication of Labor, Durham/London, Duke University Press, 2013, pp. 2-9 e 14-19.

113 Karl MARX, Der achtzehnte Brumaire des Louis Bonaparte in Marx-Engels Werke, Berlin, Dietz Verlag, 1960, vol. 8, p. 119; Carl SCHMITT, Politische Theologie cit., p. 43 e Giorgio AGAMBEN, Stato di Eccezione cit., capítulo 1 , pp. 9-43.

114 Gilberto BERCOVICI, Soberania e Constituição cit., pp. 43-46 e 327-344.
} 